\title{
Media and Terrorism as a Strategy of Psychological Warfare
}

\section{Dr. Ibrahim Ahmed}

Professor and the Head of the

Department of Educational and Psychological Sciences, Faculty of Specific Education, Mansoura University

\section{Dr. Hazem Elbana}

Assoc. Professor of Educational Radio and Television, Faculty of Specific Education, Mansoura University
By Dr. James Kiwanuka-Tondo

Associate Professor of Communication at North Carolina State University

\section{Dr. Wael Mekhemar}

Lecturer of Educational Radio and

Television Faculty of Specific

Education, Mansoura University

\section{Ahmed Elhelali}

Faculty of Specific Education, Mansoura University

\section{Research Gournal Specific Fducation \\ Faculty of Specific Fducation \\ gYansoura University}

ISSUE NO. 46, APRIL. 2017

$$
\begin{aligned}
& \text { مجلة بحوث التربية النوعية - جامعة المنصورة }
\end{aligned}
$$

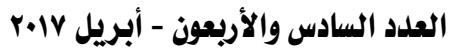




\section{Media And terrorism as a Strategy Of Psychological Warfare}

Dr. Ibrahim Ahmed ${ }^{*}$

Dr. Hazem Elbana ${ }^{* * *}$
Dr. James Kiwanuka-Tondo **

Dr. Wael Mekhemar ${ }^{* * * *}$

\section{Ahmed Elhelali ${ }^{* * * * * *}$}

\section{Abstract}

Developments in the field of media, such as the spread of reality shows related to crimes and the increasing focus on media coverage of news on violence, has an enormous influence in promoting the fear of crime. This paper mainly offers a review of the research on mass media influence on the perception of terrorism and crime threat, and it also examines the relationship between media and fear.

Keywords: terrorism, fear of terrorism, fear of crime, propaganda, psychological warfare

\section{Introduction:}

Imagine if there were no media to record what had happened on $9 / 11$. Could that act of terrorism have caused the same influence on people everywhere on earth? Because of the media attention to broadcasting every single detail of this horrifying incident, it was as if Bin-Laden had bombed a vital building in every country all over the world. Terrorists harnessed mass media to spread their act of violence and maximize the influence. Scholars argue that media has a great influence on viewers' realization of the threat of terrorism (Brinson \& Stohl, 2012). Consequently, media plays a

* Professor and the Head of the Department of Educational and Psychological Sciences, Faculty of Specific Education, Mansoura University

${ }_{* * *}^{* *}$ Associate Professor of Communication at North Carolina State University

Assoc. Professor of Educational Radio and Television, Faculty of Specific Education, Mansoura University

${ }^{\star \star \star *}$ Lecturer of Educational Radio and Television Faculty of Specific Education, Mansoura University

Faculty of Specific Education, Mansoura University 
significant role in promoting public fear of terrorism and maximizing the feeling of victimization.

Indeed, because the media always visualizes victims as innocent people with good merits (Powell, 2011), every single person - regardless of race, age, gender or religion - feels the possibility of being the next victim. Unfortunately, media has crossed the limit of reporting the information objectively and moved into spreading the terrorists' beliefs, justifications, and ideologies, which have the worst impact on people's perception of terrorists. Some people naively begin to believe that terrorists have the right cause for their actions and express sympathy with them; others - who are brainwashed- see them as heroes and tend to join them. Hypothetically speaking, mass media nowadays has become the "paparazzi" of terrorists by broadcasting whatever ideas, news, and videos the terrorist want to deliver to people.

Also, the mass media is responsible for aiding terrorist organizations and helping them to achieve their agendas. The jihadist groups have used the electronic media successfully to reach their ultimate goals. As evidence of this, ISIS has produced many videos showing the executions of hostages in a very savage way such as the videos of Foley and Sotloff to deliver certain messages made to warn US government from intervening. Obviously, ISIS is making these videos interesting to resemble an action movie to keep the viewing rate rising (Rose, 2014). Hence, it is a political war that has its wide disastrous influence on all people regardless of their different cultures, religions, race or history(Ellington, 1982).

No matter what different reasons stand behind the use of terrorist actions by each terrorist organization, these organizations are similar to each other at some points. They can be categorized into three main categories; one is ideologically-based, the second is nationalist, and the final, a hybrid of the two. However, we still have a dilemma in applying the categorization above to some of the Middle Eastern terrorist groups, for example, the case where the state itself is involved in the terrorist organization as seen in Iraq, Libya or Syria. Obviously, this terrorist state does not have its own category 
for many reasons. It is important to note that this case occurs rarely and when it does, the state often backs a particular terrorist organization that can fall under one of the previously mentioned classifications. Finally, no matter what the differences are, all terrorist organizations can be categorized through their motivations (Kuipers, 2009).

Logically speaking, it is a lame excuse after mass media racing to have the precedence of broadcasting the videos of terrorists' violent acts and get the scoop. It is ridiculous to shift the purpose of reporting news from reporting an information about terrorists' attacks merely and objectively to create a complete scenario in the sequence of a reality show in order to keep viewers aroused to whatever may happen next.

\section{Literature review}

McCombs and Shaw (1972), have concluded that the mass media has a part in directing the attitudes of public toward political issues and figures. Simply stated, the media creates the main features of any normal individual's thoughts, knowledge, and emotions.

Seib (2008) discusses how the terrorist organizations' propaganda, such as Al-Qaeda, have not only launched many videos after the 9/11 but also used more than 4,000 Web sites to strengthen their believers and horrify their targets. The scholar further suggests that the terrorist organizations found this method of communication the easiest way to create a common language for communicating with the rest of the world. The terrorist organizations realize that war is not only about bombing a building or executing a person to deliver their messages to the government concerned. It is also about spreading their beliefs and ideologies, explaining their logical justifications, and building up their militias by luring civilians to join especially from the Western world. Also, the jihadist groups use online magazines in English to affect wWestern audiences in order to entice them to join their militia. As an example, Western media placed the responsibility for certain incidents on these magazines such as the Boston Marathon bombing in 2012 (Skillicorn, 2015). It is a huge continuous battle between governments and terrorist organizations which are affected by their 
violent actions Meanwhile, the media is creating the majority of the rules of the game. (Lynch, 2006).

Others scholars argue that the jihadist groups have gone further in benefiting from this way of communication to enhance the idea of combat dogma in their allies' consciousness. Al-Qaeda promoted the idea of an attractive death and the afterlife paradise to induce their future allies to join their militias. Al-Qaeda misuses certain lines from the Holy Qur'an and Hadith to serve these goals (Baines \& O'Shaughnessy, 2014).

Nowadays, the propaganda of terrorism has expanded to include more objectives other than fear such as staying strong, avoiding repeating previous mistakes, backing up troops, and honoring the dead. This propaganda is based on mass media news related to threat and danger and on the viewers' beliefs and fear experiences (D. Altheide, 2009).The mass media is not the only player in the game of using the terrorists' attacks to achieve certain success; politicians also are accused of promoting public fear of terrorism. When a particular terrorist attack occurs, the government tends to benefit politically from the disaster the most. Consequently, the government in the first place seeks to inflate the incident by using a vague expression to describe what happened. After the 9/11 attacks on the World Trade Center and the Pentagon, President Bush used words like terrorist, terrorism, and terror in his speech, but without providing any definitive description of these words (Bigelow, 2005). Indeed, this opacity in these terms is intended as legal and political coverage to the government reactions.

Alas, the Bush government used the citizens' pain and loss to fuel their fear of that vague concept called "terrorism." The Bush government played the game well not only by avenging the Americans killed but also by achieving its political agenda towards its enemies. Obviously, it was not about taking revenge against Bin Laden and Al-Qaeda, the government used this horrifying incident to eliminate all its enemies all over the world. The Bush administration used the media to convince Americans of the benefits of implementing its radical agenda. Its agenda included increasing the tax 
rate, reducing social programs, military expansion, and the passing of legislation limiting freedoms such as the Patriot Act. The attacks were also used as a pretext for launching expanded military attacks on Iraq (Kellner, 2007).

Also, there was a serious negative impact on the legal system in the country where these attack took place because of the legislature's fear of terrorist organizations and the expansion of their violent acts. After 9/11 attacks, the Commonwealth Parliament overreacted in its fear of terrorism by legislating 44 Acts to face terrorism, which imposed an apparent limitation on human rights and freedom (McGarrity, 2011).

Unfortunately, it was easy for the mass media to spread the idea that Islamic Civilization as a whole was responsible for this incident and must pay the price. That definitely worked in favor of the Bush agenda toward the Middle East and justified the insertion of the American military anywhere in the Islamic world. Indeed, this ideology shaped the whole world perception towards the Islamic world as terrorists and bolstered continued contempt for their beliefs, thoughts, and religion. Also, it justified any act of violence committed against any Muslim either by government troops or by civilians. To sum up, the mass media is the fundamental factor in manipulating the public by monopolizing the collection of news to be reported. The method of broadcasting the news gives media prominence over any other factor in producing the fear of crime and promoting it to be the fear of terrorism.

Nellis and Savage (2012) suggested certain factors control the fear of crime, namely, the way the media handles the attacks through their broadcasting and people's interaction with and their belief in this news. The authors argued that the individuals' gender, age, race and previous personal experiences related to the attacks have a significant influence on the way they receive the news concerning the attacks, which eventually promote the fear of terrorism. Also, they concluded that the policymakers play a major role in maximizing people's fear by manipulating the news.

On the other hand, Baybars-Hawks (2009) illustrated that the triangle of terrorists' demands from governments, media coverage, and 
public opinion portrays the main features of today's terrorism. Simply stated, the media is the only tool that the terrorists use to penetrate public opinion in order to reach their ultimate goals from the concerned government. The exaggerated attention of media to terrorism leads to increasing the public concern about terrorism, which in turn, backs the terrorists in achieving their desires. Governments should learn how to ease the anxiety of their citizens and prepare them to deal with terrorism and its psychological impact to win the war against terrorism. Also, the media must stop serving the terrorist organizations' agendas through broadcasting news related to their attacks unprofessionally and subjectively (Shaw, 1979).

A study by Palmerton (1988) focused on the argument that the exaggerated influence of terrorism is mainly made through the way that others react to the terrorist act, particularly the mass media. It relates to gaining more political benefits through convincing the public that they can assure their salvation from terrorists. In reality, victims of terrorists' attacks are fewer than citizen killed by any other cause like smoking tobacco. Consequently, politicians using the rhetorical impact of terrorism on the public to gain more votes, support or financial funding, is playing an equal role to that played by media in promoting the psychological impact while the increasing of crime rate of terrorism on public.

According to Kort-Butler and Hartshorn (2011), viewing crimebased reality TV programs reflects in recipients' minds an imminent visualization of themselves as victims of these crimes, especially as the crime rate increases, which strengthens their belief in the national system of justice to be safe and peaceful. In the meantime, the media obsession in pursuing the complete scenario of the crime and tracking every victim involved promotes that feeling of victimization. Indeed, there is an inverse relationship between the increase of citizens' fear of crime and their trust in the system of criminal justice. Consequently, broadcasting detailed realistic crimes illustrates the challenges faced in encountering these crimes, which leads eventually to a melodramatic feeling in citizens' hearts that they are insecure. 
Altheide (2007) supported the idea that mass media promoted terrorism, especially after 9/11 attacks. This horrible incident was used by politicians to achieve whatever goals in the context of protecting citizens and promoting their interests. Consequently, US actions were portrayed as revenge, letting off steam or defense against barbarian, offensive, and violent acts conducted by terrorist organizations. Meanwhile, for citizens to be guaranteed safety and peace, they turned a blind eye to some actions committed by police officials that constituted aggression.

Altheide (2004) discussed the reflection of the mass media portrayal of fear and popular culture on the shifting of the terrorism meaning from being a strategy for a state of condition. Inevitably, after 9/11, the mass media broadcast all the shifts in the social and cultural definitions of these separated events known as 9/11 and terrorism. Media defined the attacks of 9/11 as a war on not only American culture but also civilization itself. Consequently, using this language gradually shifted the meaning of terrorism from a simple act of crime to a constant condition known as terrorism. Also, it supported the idea of the war against terrorism justified any action against terrorists anytime anywhere.

Becker-Blease, Finkelhor, and Turner (2008) focused on the inevitable effect of viewing media reports, especially after 9/11, in increasing individuals' worries and in changing their activities mainly those between $10-13$ years old. In conclusion, they emphasized that contrary to normality, the less the children are exposed to media, the less their reactions are. Their results also show that the children had higher levels of stress.

Snow (2007) demonstrated that terrorism is psychological warfare which uses the most efficient way to communicate with the world by utilizing horrifying images instead of threatening speech. Unfortunately, this way of communication seduces the media to race to broadcast news that is profitable and has a higher rate of viewing as opposed to the usual mundane daily news.

Montiel and Anuar (2002) illustrated that media draws the main picture of terrorism through their power of choosing which news to 
broadcast and to report to the world. This ability to choose news makes the media dominant in defining the meaning of terrorism, which inevitably penetrates the minds of people.

Callanan (2012) distinguished the effect of multiple methods of crime-related media on people regarding race using a survey research. He concluded that it is normal that viewing local television news related to crime increased the fear of crime. He reached the inference that showing nonfictional crime programming has the same effect on promoting the fear of crime while newspapers have a variable and less significant impact on recipients' understanding of crime.

Rothenbuhler (2010) stated that while covering the incidents of 9/11, media did not focus on what Bin Laden stated in such situation. Instead, the media focused on the ideology related to this horrible event; that the impossible happened without logical explanation, reporting the number of the dead and the victims. Certainly, not knowing definitively the number of the dead and their names on that morning made the attacks more horrifying and terrifying. This uncertainty successfully promoted the fear of terrorism.

Kohm, Waid-Lindberg, Weinrath, Shelley, and Dobbs (2012) raised the question of the prominence of a certain media type and the amount of viewing of certain media news to promote the fear of crime. The results showed that Canadian students' fear of the crime level is higher than American students. Although the media meant to cause a huge impact on American students' fear, the influence of media on both groups was unequal.

Kupchik and Bracy (2009) defined the way media broadcasts the issue of the crime and violence at school. The study concluded that the news showed that the worst has not come yet by portraying certain images; the potential for the tragedy at school, the fact that school violence is unanticipated, and the concept that the school should be blamed for not warning about violence. The printed news media does not provide objective coverage as it maximizes the fear of school violence without providing information about how rare it is. 
Callanan and Rosenberger (2015) analyzed the relationship between multiple forms of media focusing on crime news and the fear of crime by categorizing individuals by gender. The study's main purpose was to find out whether viewing crime-related programs has a different effect on men and women. The analysis concluded that gender or race/ethnicity caused no major difference in producing fear of crime. Consequently, media promoting the fear of crime and the feeling of victimization affects recipients equally regardless of gender or race, although the majority of victims are white females in crime-related programs.

Chadee (2005) studied the criminal activity rate in Trinidad to prove that media has no role in producing the fear of crime. Basically, the media broadcasts and publishes nonfictional crime stories through newspapers, television, and radio which have a lesser effect in promoting the fear of crime than other demographic factors such as gender, age, crime rate increase, etc.

Cho et al. (2003) discussed the major influence of realistic television crime news in producing more fear than newspapers by including huge emotional content and visual imaginary. It was obvious that television promoted and exaggerated the emotional response during the 9/11 attacks more than newspapers did. Indeed, exposure to television news produced negative emotional reactions to the attacks and increased viewers' inclination towards these emotions from exposure to any future similar television news. To conclude, it was evident that television news is completely different in the communication and the use of language from the newspaper, which produces different effects on the audience.

\section{Theoretical framework}

Runyowa (2013) defines agenda-setting as the process whereby the mass media regulates what we worry about and think. Wu and Coleman (2009) suggest that the candidates' values have a more significant effect during the voting process more than candidates' attitudes towards issues. Also, the second important effect is the negative information reported by the media about candidates' characteristics. 
Zhu (1992) explained that research about classic agenda-setting presupposed a process in which all issues come to compete to attract media and public attention. Meanwhile, the recent research ignored this hypothesis. Some sources illustrated that agenda setting is a zero-sum game, due to the narrow carrying dimensions of the public agenda. Furthermore, there is a proposed mathematical model to evaluate the strength of the two approaches. Finally, the results show that the two approaches are mutual competition for the media and public attraction.

Young (2003) stated that the recent research studied the consequences of fear for the recognized importance of news stories. It was assumed that TV news that promotes much fear is considered the most important content. He asked participants to be like TV news editors and hypothetically choose promotional news clips for an evening news broadcast. Results showed that the news stories selected as the more important ones are those which contain more controversial issues and possibly have a more personal impact than the clips not selected. This is despite the fact that the issues covered in the selected clips are familiar to them as viewers to those mentioned in the not selected ones.

Berger (2001) studied the Business Roundtable (BRT) effects on the federal policy agendas regarding four private issues. He analyzed the BRT's information on media coverage, policy agenda changes, and public opinion. Results suggest that BRT uses information backups to override the issue conflict range.

Walgrave and Van Aelst (2006) drew the broad outline of a preliminary theory to explain the political agenda-setting theory by the media which is influenced by some conditions. First, he defined the input variables of the model as; the kind of covered issues, the sort of coverage and the specific media outlet. Then, he stated that political context variables, the features of the political actors, are considered the core of the model. Finally, he concluded that the model suggests five types of output ranging from no political adoption to the fast and vital adoption of media matters. 
Shaw (1979) discussed the domination of newspapers and television in defining the meaning and the importance to stick to the diverse issues, and to the many sides of the reported political activity and of the candidates' efficiency. Research proved that agenda-setting possibly happens as a cumulative effect. Consequently, the media depends on a person's determination of what are the significant public matters, but only when the media's agenda is projected over an extended period - as an incremental effect. However, there is still nothing as disgraceful as intentional manipulation. The agenda-setting purpose of the media is considered as beneficial for the individual and society. After all, it satisfies citizens' need to guide themselves properly in regards to their environment that they comprehend to be expanding and confusing, and the media strengthen both of these understandings.

Scheufele (2000) mentioned that mass media influences audience's scale in evaluating the level of the issues' importance. Thus, these evaluations are still memorable, which is the basis for any future political judgment about potential political figures. Framing is based mainly on the prospect theory which means that the audience interpretation of a certain situation can be influenced by any trivial shift in phrasing this situation's description. Meanwhile, there is a big difference between agenda-setting by mass media and framing. While mass media is intended and reasonable, largely framing focuses on the minor changes in phrasing the situations whose effect is accidental, unforeseen or unmanageable by journalists.

\section{Discussion}

Regardless of the few points of view, such as (Chadee, 2005) point of view, which focus on the possibility that mass media does not have a significant effect on promoting fear of crime along with other factors such as gender, age, or personal experiences related to crime, the contrary is proven to be true. Specifically, (Baybars-Hawks, 2009) agreed that there are many factors that participate in shaping today's terrorism's identity including policymakers, governments' agendas, and public opinion, but media still plays the prominent role in promoting the fear of terrorism. The 
shift in terrorist organizations' means of communication with the world by using terrifying images or videos instead of hard language to deliver their messages has an important influence on the media. In this way, the terrorists' news becomes more appealing to a media world seeking profits and an increase in the viewing rate. That drives media channels to race to have an exclusive to broadcast the story or at least be the first as (Snow, 2007) proved in his study. Thus, media nowadays plays a dominant role in producing public fear of terrorism in comparison with any other factor.

Montiel and Anuar (2002) agreed that this domination is a normal outcome of media's primacy in selecting what news to broadcast and how, which allow media to paraphrase the terrorism definition. Let us take the $9 / 11$ incident as an example. With the media stressing the ideology behind this terrorist attack and the ambiguity about the number of victims, this made it more terrifying and included the incident in a bigger definition of a continuous condition called the terrorism world as concluded in the study of Rothenbuhler (2010). Consequently, the focus on tracking down all of the details of any violent attack and the use of crime based reality TV shows to create an exciting atmosphere around the violent attacks led eventually to the reinforcing of the citizens' feeling of victimization; everyone has the belief in the possibility of being a victim in any violent assault, as Kort-Butler and Hartshorn (2011) presented in their research.

Truly, this belief benefits the terrorist organizations and serves their agenda, which is to horrify the public and promote a state of instability and insecurity in order to push governments as much as possible to comply with their ultimate desires. In addition, the media play into the narrative of these organizations. In contrast, the media should cut down on the obsession with the news related to terrorist attacks. Also, the governments as well have to find a reasonable way to calm the public down and train them to face any further violent attacks psychologically in order to sabotage the terrorist organizations' plans and ease the consequences of any terrorist attack on people as stated in the study of Baybars-Hawks (2009). 
Unfortunately, the terrorist organizations are not alone in using the media maliciously to reach their goals; media accidentally works in the favor of the policymakers. Kort-Butler and Hartshorn (2011) believed that through playing the main role in promoting the public fear of crime, media helps in strengthening the public trust in the national system of justice. When a terrorist attack takes place, policymakers tend to benefit from this incident with the most to gain from the public support for whatever agenda will be applied in the future either nationally or internationally. So, Palmerton (1988) also thinks that the policymakers' role in producing fear of terrorism is not less important than the role played by media. On the national level, policymakers use terrorist incidents to guarantee more votes, enact new laws imposing freedom restrictions, collect more taxes or justify whatever encroachments made by law enforcement. On the other hand, on the international level, benefits are even more if the terrorist incidents constitute disastrous breaches of international laws and cannot be realized on a normal basis such as; taking revenge, eliminating enemies and possible opponent powers, justifying the existence of militants anywhere, increasing the military budget and realizing military expansions. Altheide (2004) provides the best definition to describe this situation in which the $9 / 11$ attacks worked accidently for the benefits of the policymakers.

Despite the disagreement of Callanan (2012), the majority of researchers, such as Cho et al. (2003), supported the idea that the visual media such as TV programs have greater influence on people's perception of terrorism and have the major role in promoting people's fear more than any other means of printed media.That is because the visual media enhance people's imagination and increase negative emotions toward the terrorist attacks. Meanwhile, whatever means the media uses to broadcast the terrorist attacks, it is undoubtedly that media plays the major role in promoting fear of crime. However, there are many factors that help in categorizing people regarding the amount of fear they experience while being exposed to media crime-related reality shows such as gender, age, race, ethnicity or personal experiences. 
Despite the different nature of men and women either physically, both experience an equal level of fear while viewing the terrorist attacks related news as proved in V. Callanan and Rosenberger (2015). The reason for this fact is that these attacks normally threaten the human survival instinct and promote the feeling of victimization for both men and women, although women are considered to be more emotional creatures than men. Regarding children's vulnerability, they show a major response to fear of terrorism even if they are exposed to news of the attacks less, as presented in the research of Becker-Blease et al. (2008). Inevitably, what affects a grown up once, affects a child twice. Indeed, media has the worst impact when it comes to children. Media's continuous interest in reporting the violent attack news and making the events more exciting boosts the violent behavior among students in schools. That leads ultimately to an increase in the violence rate in schools and media which portrays the situation in schools as a disaster by blaming the schools' administrations, as reported in Kupchik and Bracy (2009)'s study.

\section{Conclusion}

This article principally offers a review of the research on the mass media influence on the realization of terrorism and the crime threat. Also, we assay the transformers of relations between the media and fear. The ultimate truth is that media, with its platforms, is guilty of being the main participant in realizing the terrorist organizations' agendas. If not for the media intervention in the game played between the terrorists and the policymakers, people's response to the terrorist attacks would be more inconsequential than to those of any other act of violence. The media is responsible for the psychological diseases we are suffering from such as anxiety, stress, fear, or victimization, and civil society must confront this phenomenon seriously.

Further studies are required to clarify the relationship between fear of crime and terrorism, and fear of involving in the community with a deep understanding the feasibility to discriminate one or more races. Studies of the effect of fear of violence committed by police officers are also needed. 
More involving studies should focus on terrorism's use of the psychological strategies to spread fear among societies.

\section{References}

- Altheide, D. (2009). Terrorism and propaganda. Studies in Symbolic Interaction, 33, 279-296.

- Altheide, D. L. (2004). Consuming terrorism. Symbolic Interaction, 27(3), 289308.

- Altheide, D. L. (2007). The mass media and terrorism. Discourse \& Communication, 1(3), 287-308.

- Baines, P. R., \& O'Shaughnessy, N. J. (2014). Al-Qaeda messaging evolution and positioning, 1998-2008: Propaganda analysis revisited. Public Relations Inquiry, 3(2), 163-191.

- Baybars-Hawks, B. (2009). Long Term Terrorism in Turkey: The Government, Media and Public Opinion. Shona Hill \& Shilinka Smith, 63.

- Becker-Blease, K. A., Finkelhor, D., \& Turner, H. (2008). Media exposure predicts children's reactions to crime and terrorism. J Trauma Dissociation, 9(2), 225-248. doi: 10.1080/15299730802048652

- Berger, B. K. (2001). Private issues and public policy: Locating the corporate agenda in agenda-setting theory. Journal of Public Relations Research, 13(2), 91-126.

- Bigelow, B. (2005). Whose Terrorism? A classroom activity enlists students in defining terrorism and then applying their definitions to world events. The Radical Teacher, 24-30.

- Brinson, M. E., \& Stohl, M. (2012). Media framing of terrorism: implications for public opinion, civil liberties, and counterterrorism policies. Journal of International and Intercultural Communication, 5(4), 270-290.

- Callanan, V., \& Rosenberger, J. S. (2015). Media, Gender, and Fear of Crime. Criminal Justice Review. doi: 10.1177/0734016815573308

- Callanan, V. J. (2012). Media Consumption, Perceptions of Crime Risk and Fear of Crime: Examining Race/Ethnic Differences. Sociological Perspectives, 55(1), 93-115. doi: 10.1525/sop.2012.55.1.93 
- Media and Terrorism as A Strategy of Psychological Warfare

- Chadee, D. (2005). Fear of crime and the media: Assessing the lack of relationship. Crime, Media, Culture, 1(3), 322-332. doi: $10.1177 / 1741659005057644$

- Cho, J., Boyle, M. P., Keum, H., Shevy, M. D., McLeod, D. M., Shah, D. V., \& Pan, Z. (2003). Media, terrorism, and emotionality: Emotional differences in media content and public reactions to the September 11th terrorist attacks. Journal of Broadcasting \& Electronic Media, 47(3), 309-327.

- Ellington, L. (1982). Teaching high school students about political terrorism. The Clearing House, 56(4), 161-163.

- Kellner, D. (2007). Media spectacle, fear, and terrorism. Media Development, 54(3).

- Kohm, S. A., Waid-Lindberg, C. A., Weinrath, M., Shelley, T. O. C., \& Dobbs, R. R. (2012). The Impact of Media on Fear of Crime among University Students: A Cross-National Comparison1. Canadian Journal of Criminology and Criminal Justice, 54(1), 67-100. doi: 10.3138/cjccj.2011.E.01

- Kort-Butler, L. A., \& Hartshorn, K. J. S. (2011). Watching the detectives: Crime programming, fear of crime, and attitudes about the criminal justice system. The Sociological Quarterly, 52(1), 36-55.

- Kuipers, A. C. (2009). The Root Causes of Terrorism in the Middle East.

- Kupchik, A., \& Bracy, N. L. (2009). The News Media on School Crime and Violence Constructing Dangerousness and Fueling Fear. Youth Violence and Juvenile Justice, 7(2), 136-155.

- Lynch, M. (2006). Al-Qaeda's Media Strategies. The National Interest, 50-56.

- McCombs, M. E., \& Shaw, D. L. (1972). The agenda-setting function of mass media. Public opinion quarterly, 176-187.

- McGarrity, N. (2011). Fourth estate or government lapdog? The role of the Australian media in the counter-terrorism context. Continuum: Journal of Media \& Cultural Studies, 25(02), 273-283.

- Montiel, C. J., \& Anuar, M. K. (2002). Other terrorisms, psychology, and media. Peace and Conflict: Journal of Peace Psychology, 8(3), 201-206.

- Nellis, A. M., \& Savage, J. (2012). Does Watching the News Affect Fear of Terrorism? The Importance of Media Exposure on Terrorism Fear. Crime \& Delinquency, 58(5), 748-768. doi: 10.1177/0011128712452961 
- Palmerton, P. R. (1988). The rhetoric of terrorism and media response to the "Crisis in Iran". Western Journal of Communication (includes Communication Reports), 52(2), 105-121.

- Powell, K. A. (2011). Framing Islam: An analysis of US media coverage of terrorism since 9/11. Communication Studies, 62(1), 90-112.

- Rose, S. (2014). The Isis propaganda war: a hi-tech media jihad. The Guardian, 7.

- Rothenbuhler, E. W. (2010). Media Events in the Age of Terrorism and the Internet1. Revista Româna de Jurnalism si Comunicare, 5(2), 34.

- Runyowa, J. (2013). An assessment of print media influence on crisis politics 2000-2008. Bindura University of Science Education.

- Scheufele, D. A. (2000). Agenda-setting, priming, and framing revisited: Another look at cognitive effects of political communication. Mass Communication \& Society, 3(2-3), 297-316.

- Seib, P. (2008). The Al-Qaeda Media Machine. Military Review, 88(3), 74.

- Shaw, E. F. (1979). Agenda-Setting and Mass Communication Theory. International Communication Gazette, 25(2), 96-105.

- Skillicorn, D. (2015). Empirical Assessment of Al Qaeda, Isis, and Taliban Propaganda. Isis, and Taliban Propaganda (January 7, 2015).

- Snow, N. (2007). Media, terrorism, and the politics of fear. Media Development, 54(3), 17.

- Walgrave, S., \& Van Aelst, P. (2006). The contingency of the mass media's political agenda setting power: Toward a preliminary theory. Journal of Communication, 56(1), 88-109.

- Wu, H. D., \& Coleman, R. (2009). Advancing agenda-setting theory: The comparative strength and new contingent conditions of the two levels of agendasetting effects. Journalism \& Mass Communication Quarterly, 86(4), 775-789.

- Young, J. R. (2003). The role of fear in agenda setting by television news. American Behavioral Scientist, 46(12), 1673-1695.

- Zhu, J.-H. (1992). Issue competition and attention distraction: A zero-sum theory of agenda-setting. Journalism \& Mass Communication Quarterly, 69(4), $825-836$. 


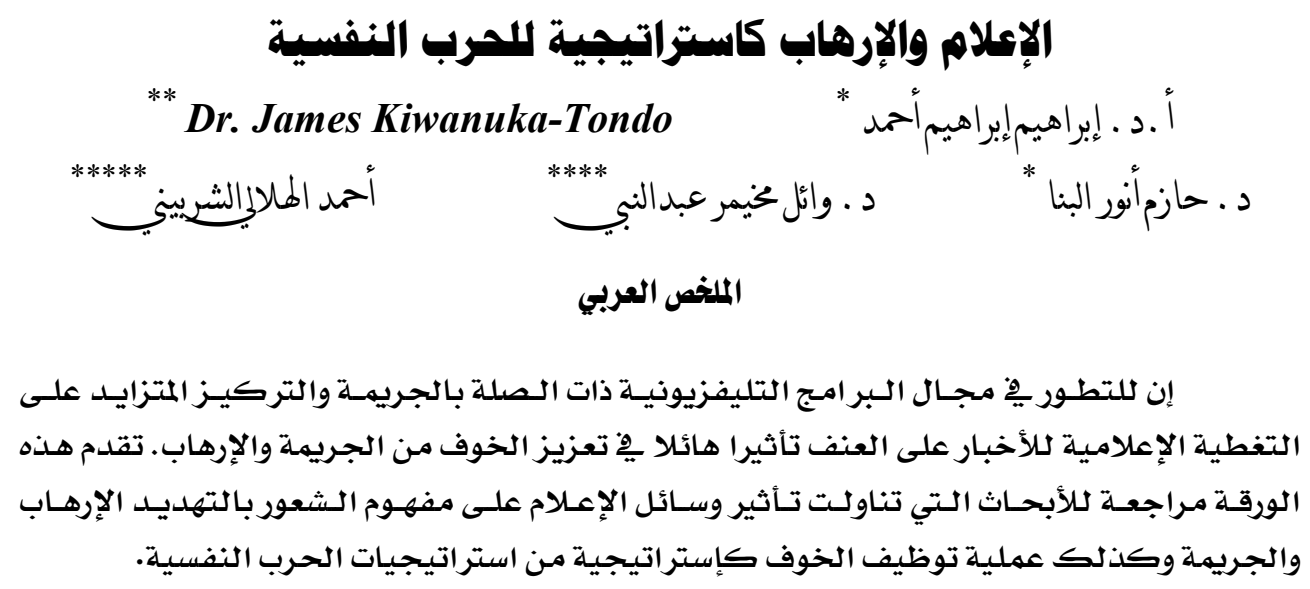

